\title{
Über den Einfluss des Placentarantiserums auf den Placentarglykogengehalt.s
}

\author{
T. Is hikawa :
(Experimentelle Studien über Eklampsie,
V. Mitteilung.
}

Von

Dr. Masao Murakami.

(村 上 正 雄)

(Aus dem Institut für Gerichtliche Medizin der Kaiserlichen

Tohoku-Universität. Vorstand: Prof. Dr. I. Ishikawa.)

\section{Inhaltsverzeichniss.}

I. Einleitung.

II. Versuchsmaterial und -methode.

III. Versuchsresultate.

1. Kapital. Kontrollversuch (mit gesunden, nicht trächtigen Kaninchen).

2. Kapitel. Eigentlicher Versuch (Trächtige Kaninchen).

IV. Zusammenfassung.

V. Schluss.

\section{Einleitung.}

Früher hatte ich in der III. und IV. Mitteilung vorliegender Untersuchung berichtet, dass das in der Placenta enthaltene Glykogen auf das Placentargift entgiftend wirkt, also der eklamptische Mutterkuchen eine weit geringere Glykogenmenge enthält und schwächer entgiftend als der normale wirkt.

Ist nun die Ursache dieses geringen Glykogengehalts der eklamptischen Placenta, wie ich vermute, darin zu suchen, dass er der Eklampsie eigentümlich ist, oder darin, dass er einfach infolge der eklamptischen Krämpfe verbraucht wird? Da mir damals kein geeignetes Versuchsmaterial zur Verfügung stand, verzichtete ich auf weitere Ver-

§ I. Mitteilung: K. Shibay a ma, Nippon Fujinka Gakkai Zasshi, 1927, 22, 575; Ir. Mitteilung: T. S a it o, dies Journ.; 1930, 15, 333; III. und IV. Mitteilung : M. M u r ak a mi, dies Journ., 1931, 18, 298 и. 320. 
suche, ohne diese Frage lösen zu können. Dass in der eklamptischen Placenta so wenig Glykogen enthalten ist, führt zu der Frage, ob dieser geringe Glykogengehalt nicht mit dem Wesen der Eklampsie zusammenhängt, mit anderen Worten, diese Tatsache lässt uns vermuten, dass sie der Eklampsie nicht eigentümlich ist, infolgedessen mindestens nicht auf die Auslösung eklamptischer Erscheinungen fördernd wirkt. Angenommen z. B., eine auf die Mutter schädlich wirkende Substanz in Foetus würde erzeugt, so würde sich, da in der Norm der Mutterkuchen entgiftend wirkt, doch kein abnormer Verlauf zeigen. Oder bei der Mutmassung, dass sich an dieser Entgiftung zum Teil das Placentarglykogen beteiligt, und bei der weiteren Annahme, dass eine solche Substanz in grosser Menge erzeugt und dadurch reichlich Placentarglykogen verbraucht wird, wodurch auch die entgiftende Wirkung abnimmt, so muss schliesslich die betreffende Substanz in den mütterlichen Organismus übergehen. Aber dieser entgiftet, wenn er gesund ist, ein solches Gift durch ein geeignetes Organ und bemüht sich natürlich, sich darin nicht stören zu lassen. Wenn man dagegen annimmt, dass er gestört ist und das Toxin nicht wegschaffen kann, dann treten Intoxikationen auf. Als solches Organ zur Beseitigung dieses Giftes könnten wir vermutungsweise die Leber betrachten, die von uns als Entgiftungsorgan für die meisten Gifte angesehen wird und deren Kreislaufsystem für die in Rede stehende Funktion geeignet zu sein scheint. Somit kommen wir zu der Vermutung, dass der Grad des Gesund- oder Nichtgesundseins der Leber die Entstehung der Eklampsie auffallend beeinflusst.

Es versteht sich von selbst, dass ich mit dieser Hypothese nicht die ganze Ätiologie der Eklampsie, sondern nur einen Teil davon erklären will. $\mathrm{Ob}$ das, wie erwartet, zutrifft oder nicht, ist experimentell zu entscheiden, und zu diesem Zwecke habe ich vorliegende Untersuchung angestellt. Ich erforschte zuerst, wie sich der Placentarglykogengehalt ändert, wenn man einem trächtigen Tiere Placentargift, dann Leber- und Placentargift zusammen zuführt. Ich wollte untersuchen, ob das Placentar- und Leberglykogen abnehmen und eklampsieartige Symptome hervorrufen.

Ich benutzte als Placentargift Placentargiftserum, als Lebergift Hepatotoxinserum und als Versuchstiere Kaninchen.

\section{Versuchsmaterial und -methode.}

\section{Darstellungsmethode des Hepatotoxinserums.}

Nach der Methode von Sakuraba yas hi') injizierte ich einer Hausente intraabdominal 1-2 g Kaninchenleberbrei mit Intervallen von 5 Tagen 17-44 mal; alle Handhabungen erfolgten steril. 11 Tage nach der letzten Injektion wurde 
das Blut entnommen und das Serum isoliert und in Ampulle verteilt, fest verschlossen und in der Eiskammer aufbewahrt.

\section{Darstellungsmethode des menschlichen Placentarantiserums.}

Die Oberfläche einer frischen menschlichen Placenta nach normaler Geburt wurde mit sterilisierter physiologischer Kochsalzlösung gut abgespült, rein abgetupft und von dem Oberflächengewebe der Fötalschicht eine ca. $3 \mathrm{~mm}$ dicke Schicht entfernt, dann wurde der Zottengewebsteil in geeigneter Grösse zerschnitten, in Kochsalzlösung getan und dieses so oft wiederholt, bis das darin enthaltene Blut entfernt war, danach wurde das Gewebe sorgfältig abgelöst, bis schliesslich fast nur noch die Zottenzellen übrigblieben. Das Ubriggebliebene wurde wiederholt mit Kochsalzlösung zentrifugiert und gewaschen, zuletzt durch Doppelgaze filtriert, das Filtrat zentrifugiert, die Zellen gesammelt und als Antigen benutzt. Von diesem Zellbrei spritzte ich einem Kaninchen je 1,3$2 \mathrm{~g}$ in Intervallen von 4 Tagen 15-25 mal ein. Die Isolierung des Serums und seine Aufbewahrungsweise sind denen beim Hepatotoxinserum gleich.

\section{Herstellungsverfahren des Kaninchenplacentarantiserums.}

Bei Kaninchen wurde in der 2. Hälfte der Trächtigkeit, besonders in deren Endstadium, der Kaiserschnitt ausgeführt und die Placenta steril ausgeschnitten. Der Mutterkuchenbau der Kaninchen unterscheidet sich dadurch von dem der Menschen, dass das maternale Placentargewebe vom fötalen leicht abgetrennt werden kaln. Bei der mikroskopischen Untersuchung fand man, dass dieses letzte fast ganz aus Zottengewebe bestand. Nur dieses wurde mit sterilisierter physiologischer Kochsalzlösung wiederholt gewaschen und entblutet, aber das Amnionstïck, die Gefässe und die anderen Interstitialgewebe wurden alle entfernt. Dieser Zottenzellbrei wurde als Antigen benutzt und einem Kaninchen 21 mal injiziert. Die Isolierung und die Aufbewahrung des Serums erfolgten auf die gleiche Weise wie beim menschlichen Placentargiftserum.

4. Die Blutbestandteile wurden nach folgenden 4 Verfahren quantitativ bestimmt:
a. der Gesamtstickstoff im Blut nach Bangs Mikromethode,
b. der Reststickstoff im Blut nach Folin,
c. der Harmstoffstickstoff im Blut nach Folin und $\mathrm{W} u$ und
d. der Blutzucker nach $\mathrm{Haged}$ or $\mathrm{n}$ und Jensen.
5. Das Glykogen wurde nach der Mikromethode von Takabatake u. Kume bestimmt.

Verwendete Tiere. Als Versuchstiere dienten immer Kaninchen. Als trächtige Kaninchen wurden nur solche verwendet, die der Verfasser selbst sich paaren liess, so dass also bei ihnen die Trächtigkeitstage bekannt waren. Den Tieren wurde in der 2. Hälfte der Trächtigkeit intraabdominal zuerst Hepatotoxinserum injiziert, dann in Intervallen von 4-5 Tagen Placentargiftserum, und 3-4 Tage nach der letzten Injektion liess man sie verbluten, worauf man möglichst schnell das Leber- und Placentarglykogen bestimmte. In der Zwischenzeit wurden nicht nur die verschiedenartigen Intoxikationserscheinungen, sondern auch die Sektionsbefunde beobachtet, auch täglich die Blutbestandteile vor und nach der Giftseruminjektion gemessen. 
Die Reihenfolge bei diesem Versuch ist aus folgender Tabelle ersichtlich:

\begin{tabular}{|c|c|}
\hline \multicolumn{2}{|r|}{ Versuchsanordnung. } \\
\hline Kaninchen $\mathrm{Nr}$. & Kontrollversuch (nichtträchtige Kaninchen). \\
\hline 1 a. 2 & Injektion von Hepatotoxinserum. \\
\hline 3 & Injektion von mensehlichem Placentargiftserum. \\
\hline 4 & Injektion von Kaninchenplacentargiftserum. \\
\hline 5 & Injektion von Hepatotoxin $\mathfrak{n}$. menschlichem Placentargiftserum. \\
\hline 6 a. 7 & Injektion von Hepatotoxin a. Kaninchenplacentargiftserum. \\
\hline Kaninchen $\mathrm{N} r$. & Eigentlicher Versuch (trächtige Kaninchen). \\
\hline 8 u. 9 & Injektion von Hepatotoxinserum. \\
\hline $10 \mathrm{u}, 11$ & Injektion von menschlichem Placentargiftserum. \\
\hline 12 น. 13 & Injektion von Hepatotoxin $u$. menschlichem Placentargiftserum. \\
\hline 14 น. 15 & $\begin{array}{l}\text { Injektion von Hepatotoxin } \mathrm{u} \text {. vorbehandeltem menschlichen Pla- } \\
\text { centargiftserum. }\end{array}$ \\
\hline 16 น. 17 & Injektion von Kaninchenplacentargiftserum. \\
\hline 18 u. 19 & Injektion von Hepatotoxin $u$. Kaninchenplacentargiftserum. \\
\hline 20 u. 21 & $\begin{array}{l}\text { Injektion von Hepatotoxin } \mathrm{u} \text {. vorbehandeltem Kaninchenpla- } \\
\text { centargiftserum. }\end{array}$ \\
\hline
\end{tabular}

\section{Versuchsergebnisse.}

1. Kapitel.

Kontrollversuch (gesunde Kaninchen, nicht-trächtig).

Beim Kontrollversuch habe ich das oben beschriebene Zellengiftserum einem gesunden, nicht- trächtigen Kaninchen injiziert und die allgemeinen Reaktionen und Symptome beobachtet.

i. Injektion von Hepatotoxinserum (Kaninchen Nr. 1 u. 2).

Nach der Injektion des Hepatotoxinserums wurden die Versuchstiere unruhig, entleerten Harn und Fäces, zeigten oberflächliche und beklemmte Atmung und Anämie der Ohrmuscheln, wälzten sich danach 30 Minuten lang und wurden unruhig, kehrten dann aber $40 \mathrm{Mi}$ nuten post injectionem beinahe zur Norm zurück.

Was die von mir bestimmten Blutbestandteile anbelangt, so schwankte das Verteilungsverhältnis des Gesamtblutstickstoffs zum Rest- und Harnstoff- $\mathrm{N}$ im 2. Fall mehr oder minder, im grossen und ganzen aber nicht bedeutend. Der Blutzucker war nach der Injektion ziemlich hyperglykämisch.

Sektionsbefund : Leber zeigt leichte Stauung, Läppchen scharf abgegrenzt, sonst im allgemeinen makro- und mikroskopisch nicht verändert. 
Tabelle I.

\begin{tabular}{l|l|l|l|l|l|l|l|l|l|l|l|l|}
\hline & \\
\hline
\end{tabular}

Der Glykogengehalt der Leber betrug $1,92 \%$ und $1,15 \%$, befand sich also im Vergleich mit dem beim normalen Kaninchen beinahe im physiologischen Bereich und war nicht besonders yermindert.

ii. Injektion des menschlichen Placentargiftserums (Kaninchen Nr. 3).

Tabelle II.

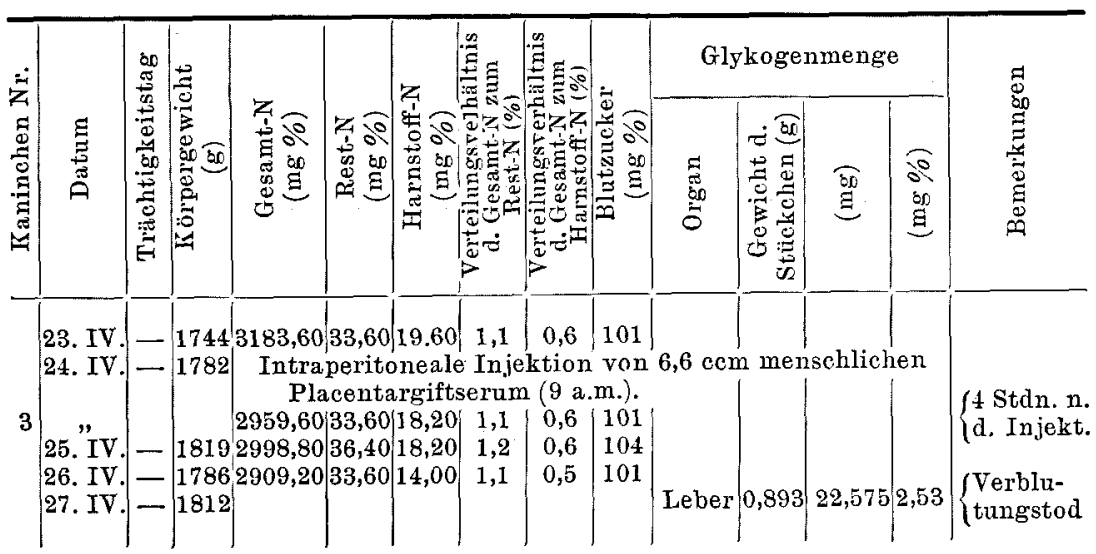


Unmittelbar nach der Injektion und auch später zeigten die Tiere ziemliche Unruhe, Harn- und Stuhlentleerung, allmählich zunehmende Unruhe, beklemmte Atmung, hyperämische Ohrmuscheln, legten sich auf den Bauch und streckten die Hinterextremitäten aus, bis sie 25 Minuten später Anzeichen der Erleichterung aufwiesen, sich nieder kauerten und nach ca. 35 Minuten wieder fast so munter wie vorher waren. Diese Symptome waren leichteren Grades als bei der Injektion von Hepatotoxinserum.

Das Rest- und Harnstoff- $\mathrm{N}$ und ihr Verhältnis zum Gesamt-N waren vor und nach der Injektion des menschlichen Placentargiftserums kaum verändert. Auch der Blutzucker befand sich im Bereich eines bestimmten Schwankungswerts.

Sektionsbefund: Leber und andere Organe gar nicht pathologisch verändert.

Die Leberglykogenmenge belief sich auf 2,53\%, blieb also im normalen Wertbereich und zeigte keine $\mathrm{Zu}$ - noch Abnahme.

iii. Injektion von Kaninchenplacentargiftserum (Kaninchen Nr. 4).

Tabelle III.

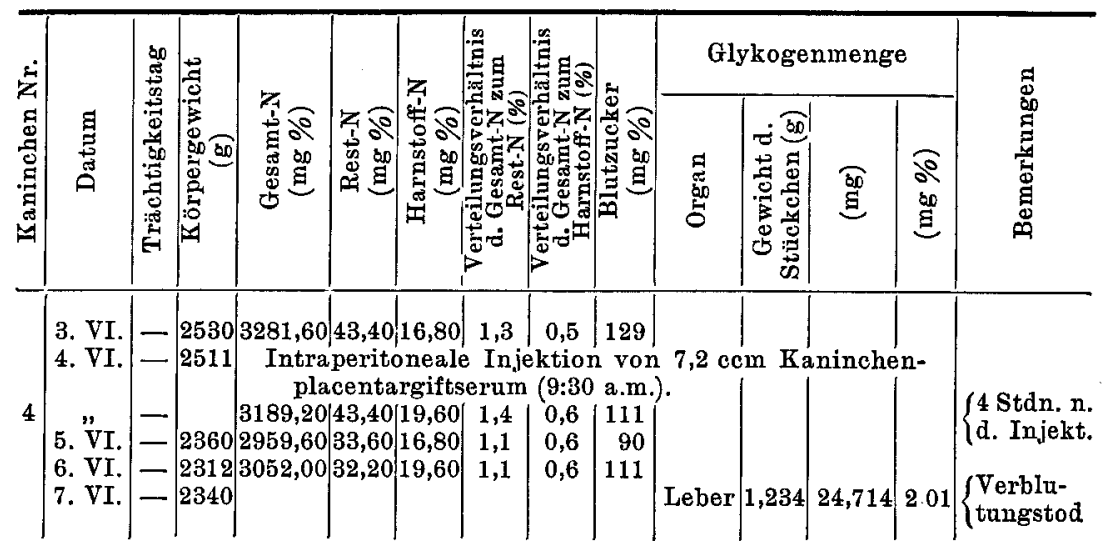

Unmittelbar nach der Injektion wurden Harn und Stuhl entleert, allmählich verschlimmerten sich die Symptome, die ca. 15 Minuten post injectionem ihren Höhepunkt erreichten; die Respiration wurde seichten und beklemmt, die Ohrmuscheln hyperämisch, die Tiere legten sich auf die Seite, die Hinterextremitäten bekamen Krampf und wurden öfters weggestreckt; nach ca. 20 Minuten trat geringe Besserung ein, die Atmung wurde regelmässig, das Tier kauerte sich wieder oder legte 
sich auf die Seite und kehrte in 40 Minuten beinahe zur Norm zurück.

Der Reststickstoffgehalt des Bluts nahm etwas ab, sein Harnstickstoffgehalt aber blieb unverändert. Der Blutzucker zeigte nach der Injektion dieses Serums eine gewisse Verminderung.

Sektionsbefund : In der Umgebung jedes Leberläppchens zeigen sich zerstreut hellbraune ungefähr reiskorngrosse, runde oder ellipsoide Teile. Kein Ikterus zu bemerken. Bei der mikroskopischen Untersuchung dieser grauen Stelle findet man, dass sie deutlich gangränös, die Leberzellenstränge unklar angeordnet, die Grenzen zwischen allen Zellen verschwunden und die Zellkerne schlecht gefärbt sind, dass also die Leber durch Injektion von Kaninchenplacentargiftserum organisch geschädigt ist, Auch beim Vorhandensein solcher ziemlich auffallender histologischer Veränderungen zeigt der N-Gehaltkeine Schwankungen, was wohl daher kommt, dass, wie Pearce u. Jack on $^{2}$ meinen, der Leber eine sehr starke Kompensationswirkung zukommt.

Der Leberglykogengehalt betrug 2,01\%, war also beinahe normal.

iv. Injektion von Hepatotoxin und menschlichem Placentargiftserum (Kaninchen Nr. 5).

Tabelle IV.

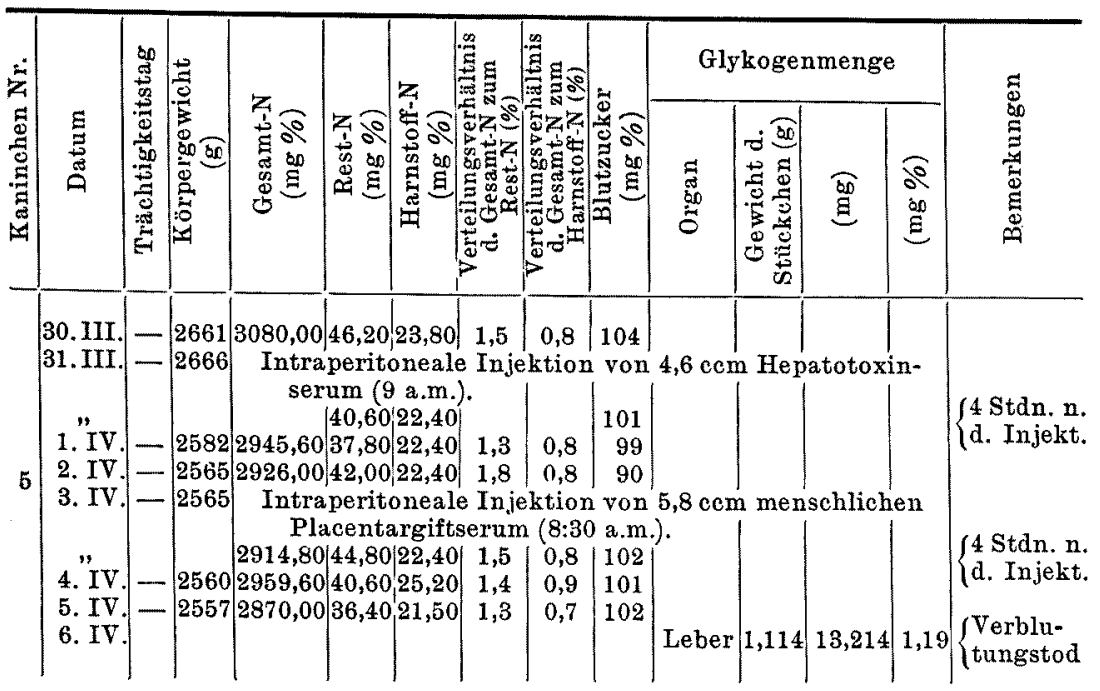

Das unmittelbar nach der Einspritzung von Hepatotoxinserum aufgetretene Syndrom ging 40 Minuten post injectionem zurück, und das Tier wurde wieder munter. Als ihm 5 Tage danach aufs neue men- 
schliches Placentargiftserum injiziert wurde, zeigte es ebenfalls sofort post injectionem Unruhe, beklemmte Atmung, hyperämischen Ohrmuscheln usw., also Symptome wie die oben beschriebenen, und schliesslich noch Krampfanfälle; hingegen erholte es sich nach der zweiten Einspritzung, im Gegensatz zu vorher, relativ schnell, d. h. 20 Minuten post injectionem verschwanden die Symptome, und innerhalb von 30 Minuten kam das Tier beinahe zur Norm zurück.

Das Blut wies durch die Injektion aller Seren mehr oder minder grosse Schwankungen in der Verteilung des Blut-N auf, aber keine so starken, dass dadurch an Stoffwechselstörung gedacht werden könnte. Der Blutzucker neigte nach der ersten Einspritzung zur Abnahme, veränderte sich aber bei der zweiten gar nicht.

Sektionsbefund : Leber an der Oberfäche glatt, normal konsistent, keinen Ikterus zeigend, an der Schnittfläche nicht abnorm. Mikroskopische Untersuchung ergab an den Rändern der Läppchen einige kleine, zirkumskripte gangränöse Stellen. In anderen Organen makroskopisch keine pathologische Veränderung nachweisbar.

Dass Leberglykogen betrug $1,19 \%$, ein Gehalt, der gegen den normalen Wert gehalten, an Abnahme, wenn auch geringe, denken lässt.

\section{v. Injektion von Hepatotoxin und Kaninchenplacentar- giftserum (Kaninchen Nr. 6 u. 7).}

Spritzt man 4 Tage nach der Injektion von Hepatotoxinserum aufs neue Kaninchenplacentargiftserum ein, so sind die dabei einsetzenden

Tabelle V.

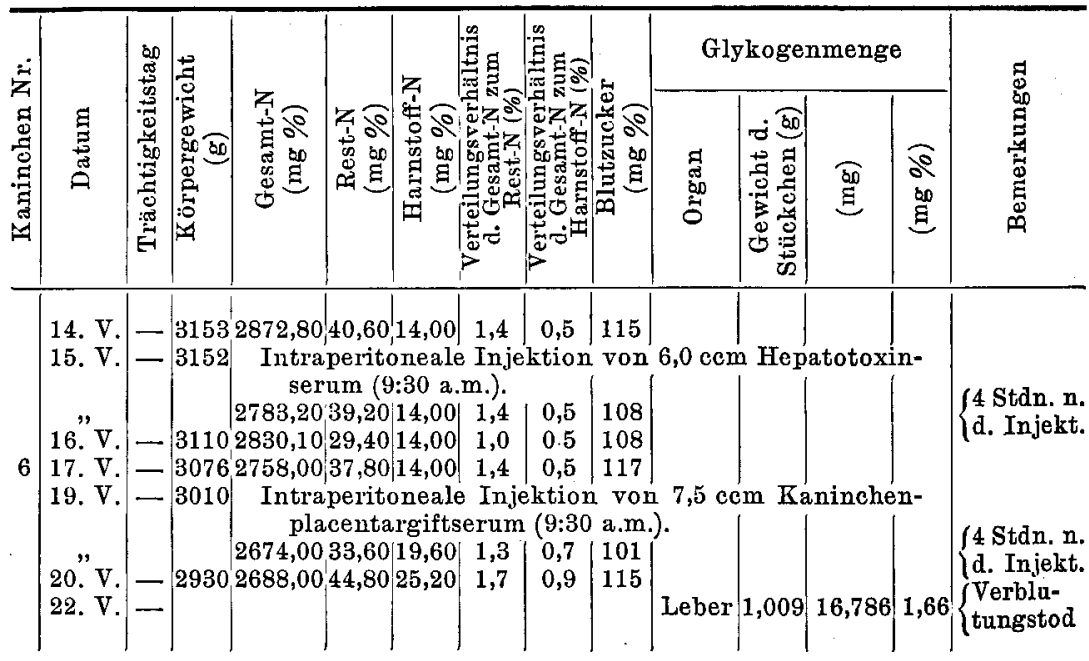




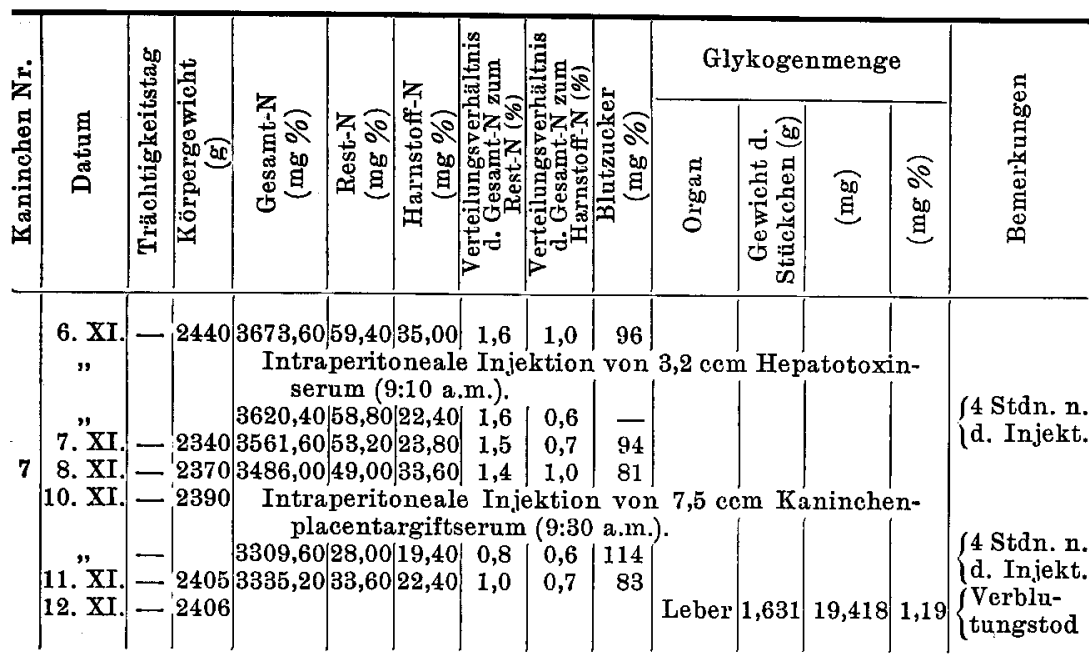

Symptome etwas heftiger als bei der Einspritzung des oben besprochenen menschlichen Placentargifts. Die Kaninchen lagen auf der Seite, machten laufähnliche Bewegungen, und die Erscheinungen wurden so stark, dass sie krampfähnlichen Anfällen ähnelten. In $35 \mathrm{Mi}-$ nuten stellte sich der normale Zustand wieder ein.

Das Rest- und Harnstoff-N usw. änderten sich gar nicht, waren auch nach der 2. Injektion beinahe normal.

Der Sektionsbefund liess keine bedeutende Veränderung erkennen.

Das Leberglykogen betrug $1,66 \%$ und $1,19 \%$, Werte, die im Vergleich zu den normalen immer im physiologischen Schwankungsbereich blieben.

\section{vi. Zusammenfassung.}

Die Versuche an nicht- trächtigen Kaninchen ergaben folgendes : Nach der Injektion von Hepatotoxinserum und Placentargiftserum in Kaninchen entstanden Unruhe, Seitenlage, seichte Atmung, Harnlassen, Stuhlgang, Streckung der Hinterextremitäten und laufähnliche Bewegungen, die alle nach ca. 40 Minuten zur Norm zurückkehrten. Auch bei der Doppelinjektion von Hepatotoxin und Placentargift war derselbe Verlauf, ohne dass sich dabei besonders an Krämpfe erinnernde Erscheinungen zeigten. Die Blut- und die histologischen Befunde zeigten kaum nennenswerte Veränderungen. Einige Leberläppchen liessen in der Peripherie gangränähnliche Befunde erkennen, aber sonst nichts Abnormes. Auch die Schwankungen des Leberglykogens blieben innerhalb des physiologischen Gebiets.-Kurz, durch die Injektion dieser Immunseren stellen sich klinisch Beschwerden ein, aber 
an den Organen keine auffallenden organischen Veränderungen, ebensowenig an den Blutbestandteilen. Das oben Besprochene sind die Ergebnisse der Kontrollversuche vorliegender Untersuchung.

\section{Kapitel.}

Eigentlicher Versuch (trächtige Kaninchen).

Die im vorigen Kapitel geschilderten Kontrollversuche haben festgestellt, dass bei nicht trächtigen Kaninchen durch per injectionem gegebenes Hepatotoxin und Placentargiftserum keine eklampsieartige Erscheinungen einsetzen und dass sich auch die Leber histologisch und $\mathrm{ihr}$ Blut chemisch nicht sehr verändern. Deshalb ging ich noch einen Schritt weiter und untersuchte trächtige Kaninchen.

i. Injektion von Hepatotoxinserum (Kaninchen Nr. 8 u. 9).

Tabelle VI.

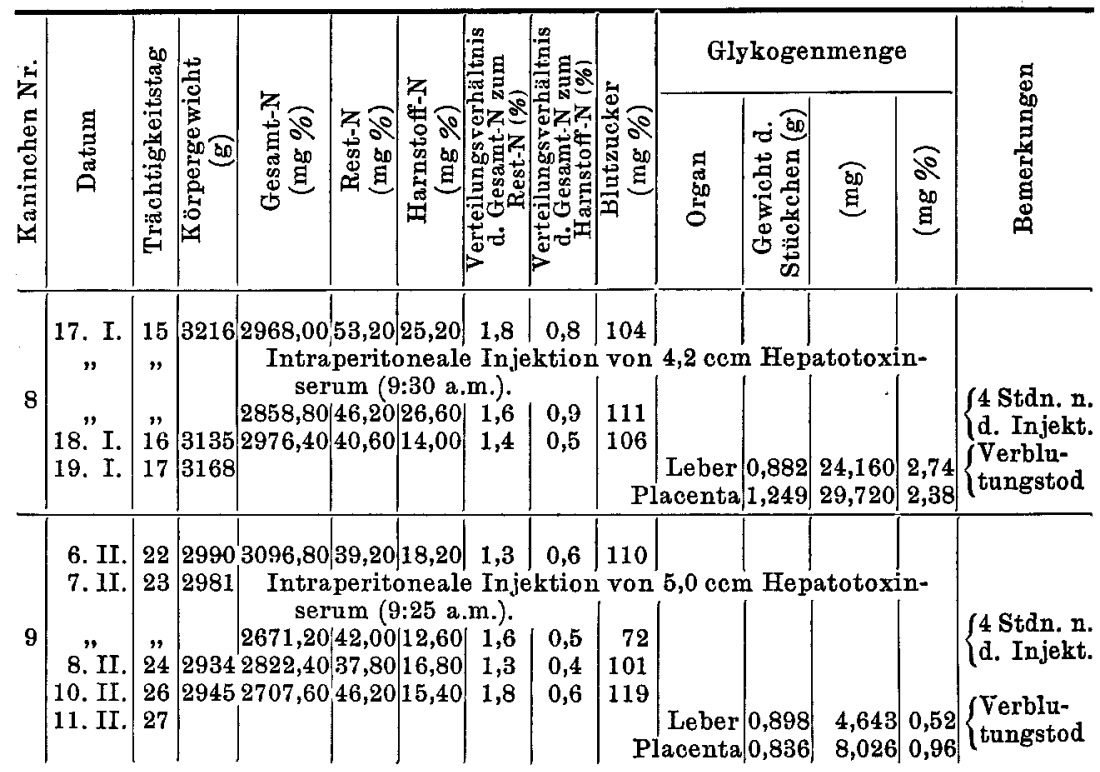

Ungefähr 10 Minuten nach der Einspritzung von Hepatotoxinserum wurden die Bewegungen schlaff, danach zeigten sich keine Veränderungen, zuweilen legten sich die Tiere auf den Bauch oder atmeten beklemmt, aber 60 Minuten post injectionem wurden sie wieder munter; die Symptome waren also leichteren Grade als bei den Kontrolltieren. 
Das Blut zeigte einerseits ziemliche Abnahme des Rest- und Harnstoff- $N$, besonders bei diesem, andererseits Neigung zur Zunahme des ersten, wobei sich dann das Harnstoff- $\mathrm{N}$ nur wenig verminderte. Der Blutzucker nahm sofort post injectionem temporär ab.

Bei derSektion liess sich keine krankhafte Veränderung bemerken.

Bei den Kaninchen betrug am 17. Trächtigkeitstage der Leberresp. Placentarglykogengehalt $2,74 \%$ resp. $2,38 \%$, also so gut wie normale Werte, aber am 27 . Trächtigkeitstage war der erste $0,52 \%$, ein sehr verminderter Wert, der an den Einfluss des injizierten Hepatotoxinserum erinnert; der Glykogengehalt des Mutterkuchens belief sich auf $0,96 \%$, also ein normal gebliebener Wert.

\section{ii. Injektion menschlichen Placentargiftserums}

(Kaninchen Nr. $10 \mathrm{u} .11$ ).

Tabelle VII.

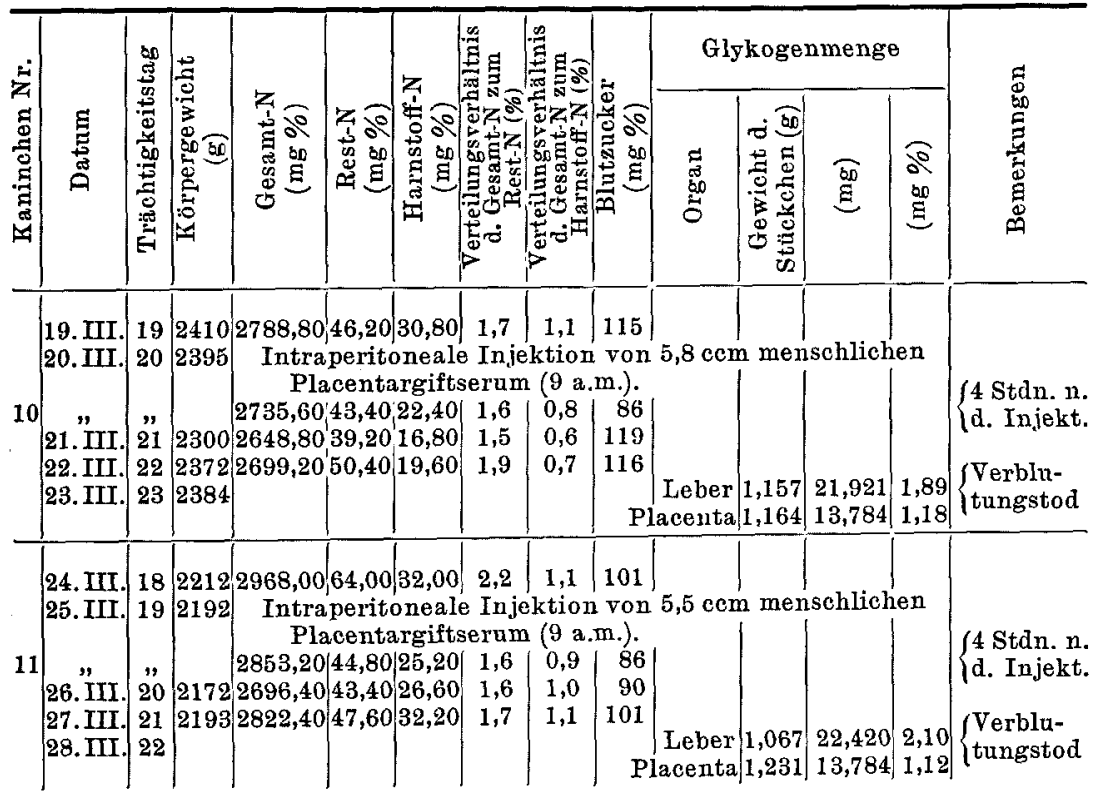

Kaninchen Nr. 10 legte sich 15 Minuten nach der Injektion nieder, wälzte sich, zeigte Atembeklemmung und hyperämische Ohrmuscheln und schwache Zyanose und kehrte 40 Minuten post injectionem beinahe zur Norm zurück, ohne je Krampfanfälle zu bekommen. Beim Kaninchen Nr. 11 waren die Symptome sehr leichten Grades.

Was die Blutbefunde betrifft, so veränderte sich das Rest-N wenig, 
aber das Harnstoff-N nahm manchmal etwas ab, und das $\mathrm{N}$ war im allgemeinen nicht abnorm verteilt. Der Blutzucker verminderte sich in der 4. Stunde post injectionem vorübergehend, kehrte aber am nächsten Tage wieder zur Norm zurück.

Sektionsbefund: Leber normal gross, normal konsistent, an der Oberfläche glatt, aber in den Leberläppchen zerstreut hirsekorn- bis halbreiskorngrosse, scharf begrenzte, graue, degenerierte Gewebspartien; die Placenta nicht auffallend verändert.

Der Glykogengehalt der Leber belief sich auf $1,89 \%$ und auf $2,10 \%$, war also normal, aber der Glykogengehalt der Placenta betrug 1,18\% und $1,12 \%$, zeigte also gegenüber dem des Mutterkuchens bei trächtigen Normalkaninchen (vgl. 1. und 2. Mitteilung!) deutliche Abnahme.

\section{iii. Injektion von Hepatotoxin und menschlichem Placentar- giftserum (Kaninchen Nr. 12 u. 13).}

Tabelle VIII.

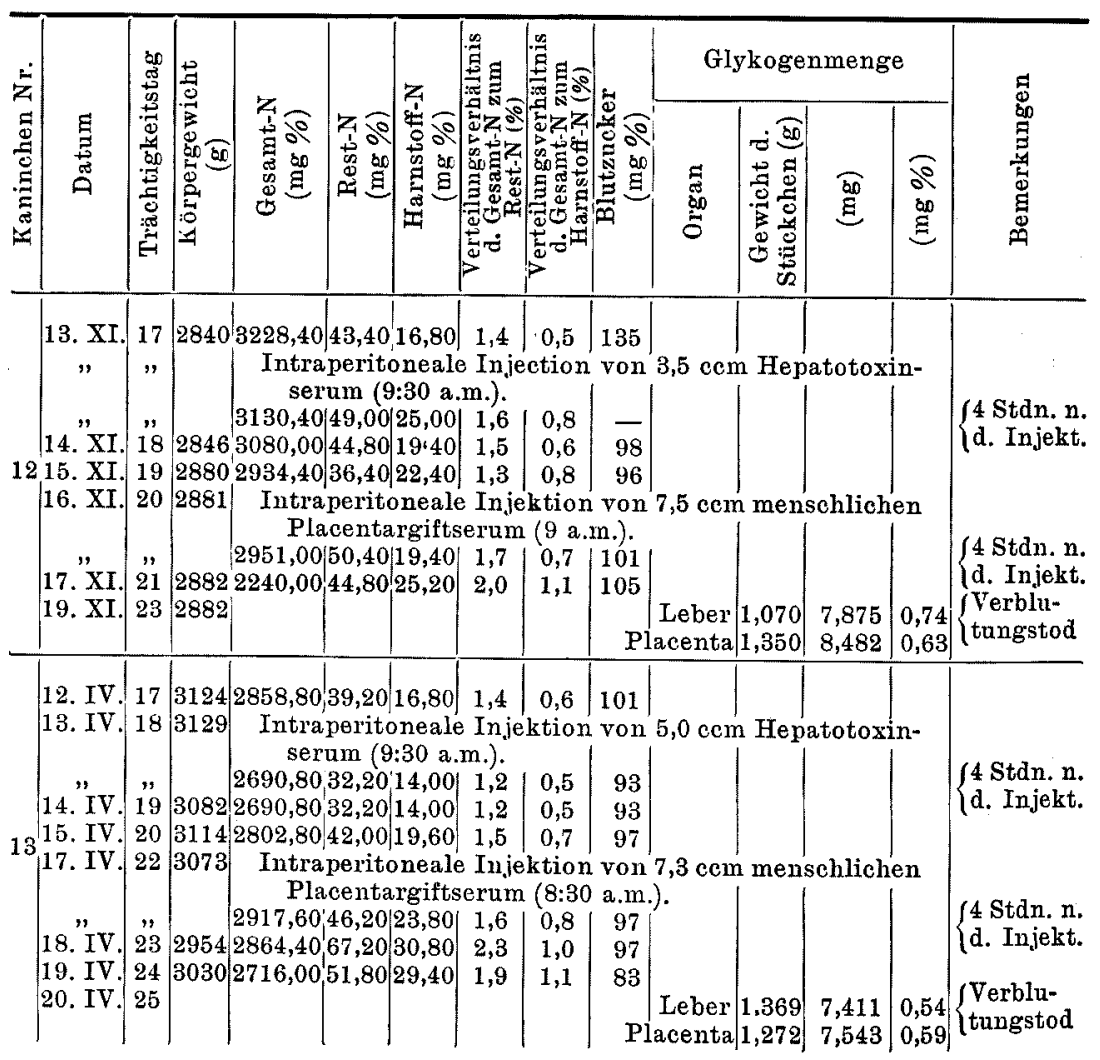


Kaninchen Nr. 12 zeigte von ungefähr 5 Minuten nach der Injektion von Hepatotoxinserum Erscheinungen, die an die beim vorigen Fall geschilderten typischen Symptome erinnern, wurde aber schon 30 Minuten post injectionem wieder munter und reagierte bei erneuter Injektion, aber einer Injektion menschlichen Placentargiftserums, 3 Tage danach viel schwächer darauf, war nur ca. 10 Minuten lang ziemlich unruhig und ängstlich, danach jedoch dauernd ruhig, legte sich dann und wann plötzlich auf die Seite, als ob es von starken Schmerzen heimgesucht würde, erholte sich aber in ca. 40 Minuten und reagierte nur noch ganz schwach, so dass es schliesslich keine Krampfanfälle bekommen konnte. Beim Kaninchen Nr. 13 waren die Symptome nach der Einspritzung von Hepatotoxinserum ziemlich heftig. Als ihm in Intervallen von 4 Tagen menschliches Placentarserum injiziert wurde, begann es unmittelbar danach beklemmt zu atmen, sich auf die Seite zu legen, Harn und Kot zu entleeren ; 15-30 Minuten hindurch waren die Symptome am heftigsten, das Tier legte sich auf die Seite, machte mit den Hinterextremitäten öfters Bewegungen, die dem Laufen sehr ähnlich waren, in dieser Zeit schien es an heftigen Schmerzen zu leiden und zeigte gerade an der Bauchwand und den Hinterextremitäten krampfähnliche starke Streckungen. Das Tier wurde nach ca. 45 Minuten etwas gebessert und allmählich immer besser und kehrte dann nach 60 Minuten zur Norm zurück.

Der Blutbefund zeigte, dass das Rest- und das Harnstoff-N post injectionem mehr oder minder stark zur Vermehrung zu neigen schienen und das Gesamt-N etwas abnahm. Der Blutzucker neigte im grossen und ganzen zur Abnahme.

Sektionsbefund: Bei einem Tiere mit schwachen Symptomen waren einige Placentae rotbraun gefärbt, an dem Grenzbezirke des maternalen Placentargewebes mit dem fötalen fand sich eine Art Erweichung, aber bei einem andern Tier mit heftigen Erscheinungen kamen an der serösen Fläche der Lunge und der Brusthöhle stecknadelkopfgrosse Blutungspunkte zerstreut vor. Die Placentae waren zur Hälfte hellbraun gefärbt, was auf den Tod des Gewebes schliessen lässt.

Was das Glykogen anbelangt, so betrug der Glykogengehalt der Leber resp. der Placenta beim Tier am 23. Trächtigkeitstage 0,74\% resp. 0,63\%, Werte, die im Vergleich mit denen beim Kontrolltiere sehr vermindert sind; besonders ist dies beim Placentarglykogen der Fall. Am 25. Trächtigkeitstage kam das Leber- resp. das Placentarglykogen in einer Menge von 0,54\% resp. 0,59\% vor. Auch dieser Fall zeigt gegenüber der Kontrolle erhebliche Abnahme. 
iv. Injektion von Hepatotoxin und vorbehandeltem menschlichem Placentargiftserum (Kaninchen Nr. 14 u. 15̃).

Tabelle IX.

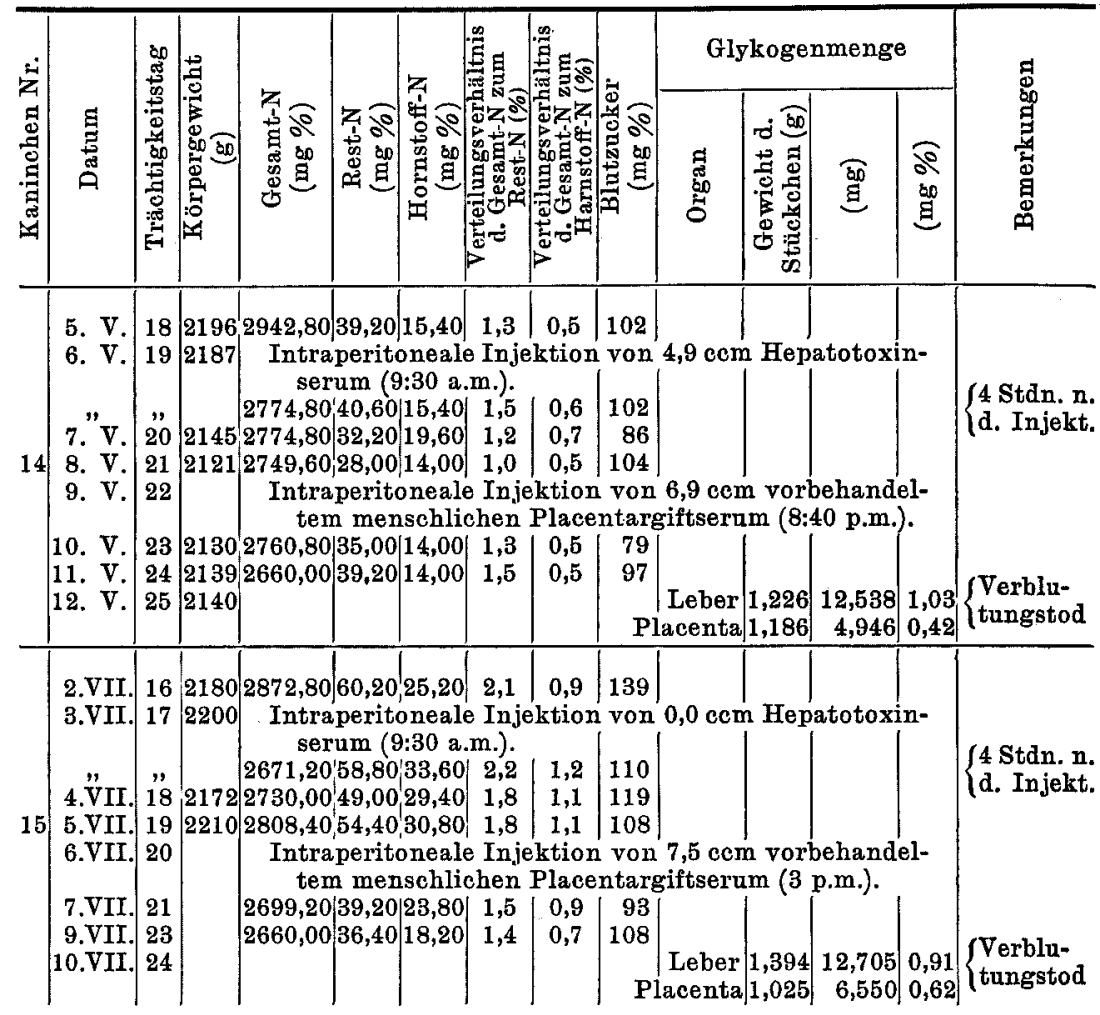

Unter der Annahme, dass man möglicherweise durch Verdauung der menschlichen Placentarzellen seitens des menschlichen Placentargiftserums die Toxicität der ersten noch verstärken kann, liess ich das letzte 4 Stunden lang im Brutschrank bei $37^{\circ} \mathrm{C}$ auf die menschlichen Placentarzellen einwirken, zentrifugierte dann das Verdaute und spritzte das oben stehende Serum ein.

Als ich nach der Injektion des Hepatotoxinserums nach einem Intervall von 3 Tagen obiges vorbehandeltes menschliches Placentargiftserum injizierte, begannen unmittelbar danach Unruhe, Miktion, Defäkation und frequente Atmung, die sich allmählich verschlimmerten; nach der Injektion wurden 15-20 Minuten lang die Symptome am heftigsten, die Tiere legten sich auf die Seite, zeigten öfters heftige Un- 
ruhe, führten mit den Hinterextremitäten laufähnliche Bewegungen aus, hatten zuweilen an der Bauchwand und den Hinterextremitäten tetanische Streckungen; nach ca. 40 Minuten besserten sich die Erscheinungen. Kaninchen Nr. 15 wurde 4 Tage nach der Einspritzung des Hepatotoxinserums das vorbehandelte menschliche Placentargiftserum injiziert, worauf es nur unbedeutende Vergiftungserscheinungen aufwies; wenn es auch post injectionem 15-30 Minuten lang unruhig aussah, so trat doch kein krampfähnlicher Anfall auf, dann hörten alle Erscheinungen auf, und das Tier wurde 45 Minuten nach der Injektion wieder munter.

Im Vergleich zu den intensiven Intoxikationserscheinungen waren die Blutveränderungen nur schwach: der Blutstickstoff war nur schwach verändert, das Gesamt-N deutete nur geringe Abnahme an, aber das Rest- und das Harnstoff-N waren kaum verändert. Auch beim Kaninchen Nr. 15 nahmen nach der zweiten Injektion das Restund das Harnstoff-N parallel zueinander ein wenig ab, zeigten sonst nichts Abnormes. Der Blutzucker zeigte im grossen und ganzen post injectionem Neigung zur Abnahme.

Sektionsbefund: Lungen, Herz, Leber, Nieren usw. nicht abnorm, Placenta blassrot gefärbt, aber nicht pathologisch verändert.

Der Glykogengehalt der Leber resp. des Mutterkuchens betrug. beim Kaninchen Nr. 14 (25. Trächtigkeitstag) 1,03\% resp. 0,42\%; das Leberglykogen nahm sehr wenig, aber das Placentarglykogen bedeutend ab. Beim Kaninchen Nr. 15 (24. Trächtigkeitstag) verminderten sich beide auffallend, das Leberglykogen betrug $0,91 \%$ und das Placentarglykogen $0,62 \%$, also dieses nahm besonders stark ab.

Das mit Placentarzellen behandelte menschliche Placentargiftserum erwies sich nach diesem Versuche in seiner Wirkung als kaum verstärkt. Kurz, nach Injektion von Hepatotoxin oder Placentargiftserum allein waren die Störungserscheinungen bei trächtigen Kaninchen leichten Grades, so dass keine spezifischen Zeichen einsetzten, während bei der Injektion beider Zellengiftseren in ein und dasselbe trächtige Kaninchen nach 3-4 Tagen bedeutend verstärkte Vergiftungserscheinungen auftraten, die krampfähnlichen Symptome und das Glykogen in den Organen auffallend abnahmen und vermutlich Erscheinungen, die denen bei menschlicher Eklampsie ähneln, einsetzten. Nicht trächtige Kaninchen zeigen solchen Zustand nicht.

\section{จ. Injektion von Kaninchenplacentargiftserum}

(Kaninchen Nr. 16 u. 17).

Kaninchen Nr. 16 zeigte unmittelbar nach der Injektion und danach Angst, legte sich dann 25 Minuten lang öfters abwechselnd auf 
Tabelle $\mathrm{X}$.

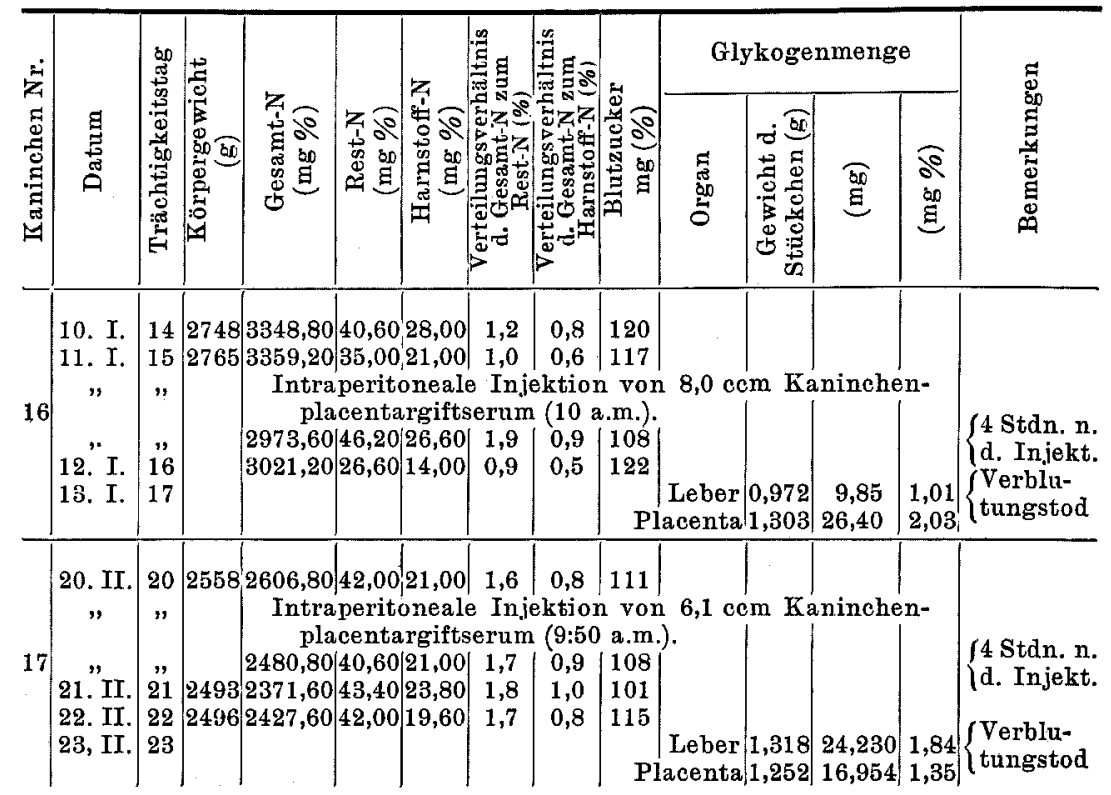

den Bauch und auf die Seite, atmete seicht und beklemmt und machte einige Male brechähnliche Bewegungen; 35 Minuten post injectionem besserten sich die Symptome. Kaninchen Nr. 17 fing post injectionem an, sich stark zu ängstigen, sich bald auf die, bald auf jene Seite zu legen und mit den Hinterextremitäten laufähnliche Bewegungen auszuführen. Nach ca. 30 Minuten wurden die Symptome etwas besser, aber noch zeigten sich anfallsweise an der Bauchwand abnorme Zukkungen.

Das Blut schien kaum beeinflusst zu sein. Die Blutzuckermenge zeigte post injectionem nur geringe Neigung zu vorübergehender $A b$ nahme.

Sektionsbefund: Tier Nr. 16 wies an Leber, Placenta und anderen allgemeinen Organen gar keine krankhaften Veränderungen auf, aber bei Nr. 17 war das fötale Placentargewebe fast zur Hälfte der Früchte blassrot gefärbt, und an der Oberfläche waren mehrere stecknadelkopfgrosse, punktförmige Blutungsherde zu sehen.

Der Leber- resp. der Placentarglykogengehalt betrug beim Kaninchen am 17. Trächtigkeitstage $1,01 \%$ resp. 2,03\%, ist also gegenuiber dem bei der Kontrolle etwas vermindert. Am 23. Trächtigkeitstage belief sich der erste auf 1,84\%, der letzte auf $1,35 \%$, sie sind also unverändert. 
vi. Injektion von Hepatotoxin und Kaninchenplacentargiftserum (Kaninchen Nr. 18 u. 19).

Tabelle XI.

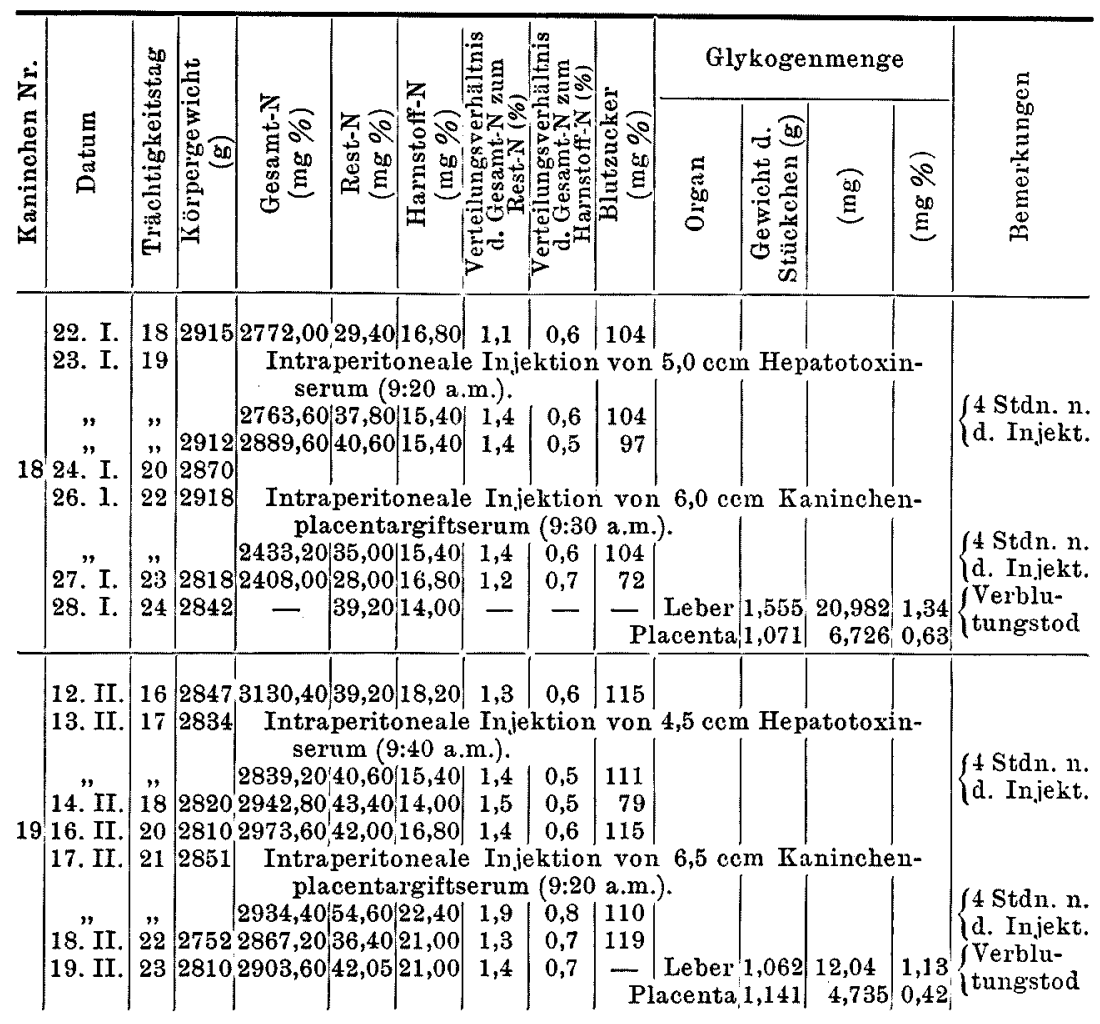

Dem Kaninchen Nr. 18, bei dem die Symptome nach Hepatotoxinseruminjektion wie bei den anderen Tieren waren, wurde nach einem $Z$ wischenraum von 4 Tagen aufs neue Kaninchenplacentargiftserum eingespritzt, wonach das Tier sofort heftige Angstzustände aufzuweisen begann, sich hin und her wälzte, nicht still stand, Harn und Kot entleerte und so beklemmt atmete, dass die Atmung bald zum Stillstand zu kommen schien. Post injectionem war die Wirkung 20-25 Minuten hindurch am heftigsten, $d$. h. es zeigten sich mehrmals tetanische Streckungen der Hinterextremitäten, abnorme Zuckungen an der Bauchwand usw., also spastische Zustände; nach etwa einer Stunde stellte sich der normale Zustand wieder ein. Also waren die Intoxikationserscheinungen bei diesem Kaninchen sehr heftig. Auch Ka- 
ninchen Nr. 19, dem nach der Injektion von Hepatotoxinserum 4 Tage später Kaninchenplacentargiftserum injiziert wurde, verfiel wie das vorige (Nr. 18) bald nach der Injektion in Angst, zeigte Atembeklemmung und hyperämischen Ohrmuscheln. Nach der Injektion wurde das Tier 10-30 Minuten hindurch von ziemlich heftigen Symptomen befallen, wälzte sich und zeigte als Höhepunkt mehrmals an der Bauchwand abnorme Bewegungen wie Zuckungen, wurde 40 Minuten post injectionem etwas besser urd kehrte nach 60 Minuten zur Norm zurück. In diesen beiden Versuchen war die Wirkung immer heftig und traten krampfartige Erscheinungen ein.

Alle N-Arten des Bluts waren mehr oder minder verändert, aber, von ihrem Verteilungsverhältnis zum Gesamt- $\mathrm{N}$ aus betrachtet, konnte kaum eine Veränderung erkannt werden. Der Blutzuckergehalt nahm bei Nr. 18 nach der zweiten Einspritzung vorübergehend ab, veränderte sich aber bei Nr. 19 kaum.

Sektionsbefund: Leber und Mutterkuchen sind nicht beträchtlich verändert, aber jene ist bei Nr. 19 etwas gelb gefärbt. Mikroskopisch sieht man in der Peripherie der Leberläppchen unregelmässig angeordnete Zellengruppen, deren Leberzellen unscharf abgegrenzt oder von verschiedener Grösse sind. In mehr als der Hälfte der Placenta zeigten sich im fötalen Placentargewebe mehrere punktförmige Blutungsflecke.

Bei dem Tiere betrug am 15. Trächtigkeitstage das Leber- resp. Placentarglykogen 1,34\% resp. 0,63\%, Werte, die im Vergleich mit denen der Kontrolle zeigen, dass jenes sich im normalen Schwankungsbereich befindet, aber dieses bedeutend vermindert ist. Das Leberglykogen zeigte am 23 . Tage $1,13 \%$ und das Placentarglykogen $0,42 \%$, was darauf hinweist, dass jenes beinahe im normalen Bereich der Schwankungswerte liegt, aber dieses beträchtlich abgenommen hat.

vii. Injektion von Hepatotoxin und vorbehandeltem Kaninchenplacentargiftserum (Kaninchen Nr. 20 u. 21).

Ebenso wie beim menschlichen Placentargiftserum liess ich Kaninchenplacentargiftserum + Kaninchenplacentarzellèn 4 Stunden lang im Brutschrank bei $37^{\circ} \mathrm{C}$ liegen, zentrifugierte dieses Gemisch und benutzte das oben stehende Serum.

Dem Kaninchen Nr. 20 wurde 3 Tage nach der Injektion von Hepatotoxinserum obiges Kaninchenplacentargiftserum injiziert. $15 \mathrm{Mi}$ nuten danach wurde das Tier angstvoll, bekam Atembeklemmung und hyperämische Ohrmuscheln, hatte Harnlassen und Stuhlgang und wälzte sich häufig hin und her; ab und zu legte es sich plötzlich auf die Seite und streckte die Hinterextremitäten aus, wurde nach $30 \mathrm{Mi}$ - 
Tabelle XII.

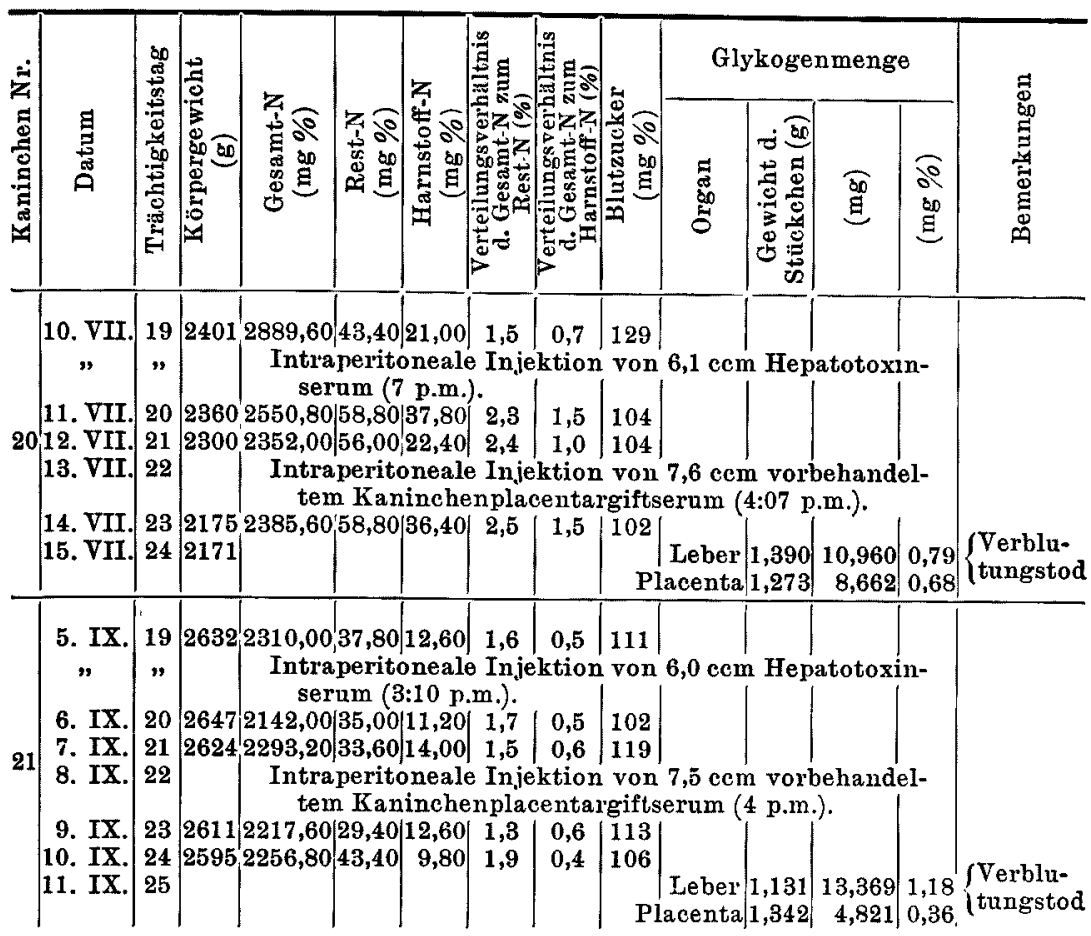

nuten besser und kehrte nach 40 Minuten zur Norm zurück. Nr. 21 wurde 3 Tage nach der Injektion von Hepatotoxinserum obiges Kaninchenplacentargiftserum injiziert, wonach leichte Symptome auftraten, d.h. nur Atembeklemmung, Wechsel der Seitenlage usw.; schon 20 Minuten post injectionem war die Norm wiederhergestellt.

Was den Blutbefund betrifft, so nahm bei Nr. 20 das Gesamt-N $\mathrm{ab}$, dagegen das Rest- und das Harnstoff-N parallel zueinander leicht zu. Bei Nr. 21 fand sich kaum Abnormes. Der Blutzucker fiel bei Nr. 20 ziemlich, wurde aber bei Nr. 21 kaum beeinflusst.

Sektionsbefund: Nr.20 liess folgendes erkennen: Makroskopisch an der Leber keine Veränderung erkennbar, aber mikroskopisch in der Peripherie des Gewebes der Leberläppchen Leberzellenstränge unregelmässig angeordnet, zirkumskripte Leberzellendegeneration mit unscharf voneinander abgegrenzten Zellen sichtbar. Placenta und andere Organe nicht sehr verändert. Bei Nr. 21 an der Oberfläche beider Lungen mehrere stecknadelkopfgrosse Extravasationspunkte vorhanden; an der Placenta das fötale Gewebe im Farbenton nicht gleichmässig und mikroskopisch Blutungsherde sichtbar. 
Der Leber- resp. Placentarglykogengehalt der Kaninchen betrug am 24. Trächtigkeitstage $0,79 \%$ resp. $0,68 \%$, sie waren also im Vergleich mit der Kontrolle beide erheblich vermindert; am 25 . Trächtigkeitstage belief sich jener auf $1,18 \%$ und dieser auf $0,36 \%$, so dass jenes beinahe im normalen Wertbereich liegt, aber dieses beträchtlich vermindert ist.

\section{viii. Zusammenfassung.}

Die bei trächtigen Kaninchen durch Injektion von Hepatotoxinserum allein oder zusammen mit einem der Placentargiftseren hervorgerufenen Erscheinungen sind im letzten Falle ernster als im ersten besonders stark bei Kaninchenplacentarserum. Bei der kombinierten Einspritzung von Hepatotoxinserum mit Placentargiftserum erzeugt das Kaninchenplacentargiftserum schwerere Symptome als das menschliche, die besonders in Form krampfähnlicher Anfälle einsetzen und bei weitem stärker sind, als bei Hepatotoxinserum allein. Aber die Krämpfe bei Kaninchen unterscheiden sich von denen bei Menschen, so dass es leider nicht feststeht, ob es sich bei diesen Krämpfen, wie erwartet, um eklamptische handelt oder nicht. Beim Blut zeigen der Stickstoff und der Blutzucker keine bemerkenswerten Schwankungen. Auch der Sektionsbefund zeigt für die Eklampsie nichts Spezifisches. Zwar zeigen sich Leberzellnekrose, Placentarblutung usw., was aber noch nicht zum Schluss auf eklamptische Degeneration berechtigt. Das Ergebnis meines eigentlichen Versuchs, das mich am meisten fesselte, ist das Verhältnis des Leber- und des Placentarglykogengehalts. Diese beiden nehmen auch bei der Injektion des Serums allein ab, aber bei der des kombinierten, vor allem bei der des Hepatotoxinserums zusammen mit Kaninchenplacentargiftserum, nimmt das Placentarglykogen besonders beträchtlich ab.

Früher meinte ich betreffs der giftigen Wirkung des Placentargiftserums bei nicht trächtigen Kaninchen, den Kontrolltieren, dass die Unmöglichkeit, bei Nichtträchtigkeit bedeutende Giftwirkung zu erkennen, darauf beruht, dass die Giftigkeit wegen ihrer Schwäche stets latent bleibt und sich nicht äussert. Dass diese Ansicht keine unbegründete Schlussfolgerung ist, wird durch viele Experimente an trächtigen Kaninchen erwiesen. Besonders auch bei experimenteller Einspritzung des Placentargiftserums allein konnte ich in verschiedenen Formen einsetzende schädliche Wirkungen, wie Abnahme des Placentarglykogens, innere Placentarblutung oder pathologische Leberveränderungen usw. 


\section{IV. Übersicht.}

Bei der Zusammenfassung der Ergebnisse des eigentlichen Versuchs ergibt sich folgendes: Nach Injektion von Hepatotoxin und Placentargiftserum, sowohl nach der des einen als auch nach der beider zusammen zeigen die Tiere unmittelbar darauf ca. 40-50 Minuten lang Allgemeinsymptome wie Unruhe und krampfähnlichen Zustand, worin aber die verschiedenen Versuchstiere Unterschiede aufweisen. Bei der kombinierten Anwendung von Hepatotoxin und Kaninchenplacentargiftserum stellen sich die schwersten Symptome ein, die in Form von als Krämpfe anzusehenden Zuständen auftreten. Bei der Untersuchung des Bluts und der anatomischen Befunde an den Organen lassen der Gesamt-, der Rest- und der Harnstoffstickstoff usw. keine bedeutenden Veränderungen erkennen. Der Blutzucker nimmt etwas ab. Auch die anatomisch-histologischen Befunde zeigen zerstreut Nekrose der Leberzellenstränge, kleine Blutungsherde an der Placenta usw., was aber kein sicheres Bild der Eklampsie bietet.

Nun scheinen aber literarisch die Blutbefunde bei Elklampsie keiner bestimmten Richtschnur zu folgen. Von Willi a $m,{ }^{3)}$ W alt hard, Fetzer, ${ }^{5)}$ Meyers, ${ }^{\text {()) }}$ Shibayama ${ }^{7}$ und Akiya ma a ${ }^{8)}$ wird nämlich angenommen, dass bei Eklampsie das Rest-N zunimmt, aber von Hellmuth, ${ }^{9}$ Hohlweg, ${ }^{10}$ Heyneman, ${ }^{13}$ Bunker \& Mundel, ${ }^{12)}$ Stander ${ }^{13)}$ und Plass, ${ }^{1-1)}$ dass es fast normalen Wert hat und unverändert bleibt, von Zangemeister, ${ }^{152}$ Landsberg, ${ }^{16)}$ Folin, ${ }^{17)}$ Farr und William ${ }^{37}$ und Shibayama, ${ }^{7}$ dass sich der Harnstoffstickstoff bei Eklampsie mit dem Reststickstoff zusammen vermehrt, und von Plass ${ }^{14)}$ und Yamada, ${ }^{18}$ dass er sich von dem bei gesunden Schwangeren nicht unterscheidet. Auch Den eck $\mathrm{e}^{19)}$ meinte, dass die chemischen Verhältnisse des Bluts bei Eklampsie äusserst verwickelt seien.

Bei Eklampsiekranken soll die Blutzuckermenge nach Stander u. Radelet, ${ }^{13)}$ Stander u. Harrison, ${ }^{20)}$ Benthin, ${ }^{21)}$ Ryser, ${ }^{22)} \mathrm{Wi}$ den $^{23)}$ u. a. zu-, nach Titu s Dodds and Willett, ${ }^{24)}$ Titus and Lightbod $y^{25)}$ u. a. abnehmen und nach Bergsma $a^{26)}$ der Zuckerstoffwechsel nicht bedeutend schwanken. Von $\mathrm{Ob}$ at a und $\mathrm{H}$ a y a s hi ${ }^{27}$ wird angenommen, dass der Blutzuckergehalt bei Eklampsiekranken selbst nach einem Krampfanfall eine kurve Zeit lang: von dem bei den meisten Gesunden nicht sehr verschieden ist, aber im Puerperium meistens abnimmt. Da die Blutbefunde bei Eklampsie auch schon schwanken und nicht bestimmt sind, so dürfte meine auf meinen Versuchen sich ergebende Annahme, dass sie sich nicht verändern, richtig sein.

Hier seien nun zur klaren Erkenntnis der wechselseitigen Beziehungen am Glykogengehalt der Leber und Placenta nach Injektion von Leber- und Placentargiftserum beinicht- trächtigen und trächtigen 
Kaninchen die Ergebnisse aller Versuche, wie folgt, zusammengefasst.

\section{Tabelle XIII.}

Veränderung des Glykogengehalts der Leber und Placenta nach Injektion von Leber- und Placentargiftserum.

\begin{tabular}{|c|c|c|c|c|}
\hline \multirow{2}{*}{$\begin{array}{l}\text { Versuchs- } \\
\text { reiho }\end{array}$} & \multirow[b]{2}{*}{ Intraperitoneale In,jektion } & \multirow{2}{*}{$\begin{array}{l}\text { Trächtig- } \\
\text { keitstag }\end{array}$} & \multicolumn{2}{|c|}{ Glykogengehalt } \\
\hline & & & $\begin{array}{l}\text { Leber } \\
(\mathrm{mg} \%)\end{array}$ & $\begin{array}{c}\text { Placenta } \\
(\mathrm{mg} \%)\end{array}$ \\
\hline 1 & Hepatotoxinserum & - & 1,92 & - \\
\hline 2 & 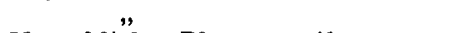 & 一 & 1,15 & 一 \\
\hline 3 & Menschliches Placentargiftserum & - & 2,53 & - \\
\hline 4 & Kaninchenplacentargiftserum & 一 & 2,01 & 一 \\
\hline 5 & $\begin{array}{l}\text { Hepatotoxin und menschliches } \\
\text { Placentargiftserum }\end{array}$ & - & 1,19 & 一 \\
\hline 6 & $\begin{array}{l}\text { Hepatotoxin und Kaninchen- } \\
\text { placentargiftserum }\end{array}$ & - & 1,66 & 一 \\
\hline 7 & $"$ & 一 & 1,19 & 一 \\
\hline 8 & Hepatotoxinserum & 17 & 2,74 & 2,38 \\
\hline 9 & & 27 & 0,52 & 0,96 \\
\hline 10 & Menschliches Placentargiftserum & 23 & 1,89 & 1,18 \\
\hline 11 & , & 22 & 2,10 & 1,12 \\
\hline 12 & Kaninchenplacentargiftser'um & 17 & 1,01 & 2,03 \\
\hline 13 & , & 23 & 1,84 & 1,35 \\
\hline 14 & $\begin{array}{l}\text { Hepatotoxin und menschliches } \\
\text { Placentargiftselum }\end{array}$ & 22 & 0,74 & 0,63 \\
\hline 15 & $"$ & 25 & 0,54 & 0,59 \\
\hline 16 & $\begin{array}{l}\text { Hepatotoxin und vorbehandeltes } \\
\text { menschliches Placentargiftserum }\end{array}$ & 25 & 1,03 & 0,42 \\
\hline 17 & " & 24 & 0,91 & 0,62 \\
\hline 18 & $\begin{array}{l}\text { Hepatotoxin und Kaninchen- } \\
\text { placentargiftserum }\end{array}$ & 24 & 1,34 & 0,63 \\
\hline 19 & . & 23 & 1,13 & 0,42 \\
\hline 20 & $\begin{array}{l}\text { Hepatotoxin und vorbehandeltes } \\
\text { Kaninchenplacentargiftserum }\end{array}$ & 24 & 0,79 & 0,68 \\
\hline 21 & $"$ & 25 & 1,18 & 0,36 \\
\hline
\end{tabular}

Wie aus obiger Tabelle ersichtlich, beträgt der Glykogengehalt bei nicht- trächtigen Kaninchen nach Einspritzung des Serums allein oder des Hepatotoxins und Placentargiftserums zusammen 1,11-2,53 $\mathrm{mg} \%$, während die Leberglykogenmenge kaum verändert ist. Aber bei trächtigen zeigte nach Injektion eines Zellengiftserums allein, sowohl des Hepatotoxinserums als auch des Placentargiftserums, ausser in einem Falle, die Leber $1,01-2,74 \mathrm{mg} \%$ und die Placenta $1,12-2,38 \mathrm{mg} \%$ Glykogen, dieses ist also sehr wenig verändert und schwankt beinahe innerhalb der normalen Werte. Ganz anders hingegen liegt es, wemn beide Zellengiftseren zusammen injiziert werden; der Glykogengehalt beider Organe vermindert sich beträchtlich, der der Leber beträgt 0,54-1,34 $\mathrm{mg} \%$ und der des Mutterkuchens $0,36-0,68 \mathrm{mg} \%$, woraus zu 
erkennen ist, dass der Einfluss auf diesen ausnahmslos stark ist. Beim Vergleich dieser Werte mit denen bei Injektion von Hepatotoxin zusammen mit menschlichem Placentargiftserum oder mit Kaninchenplacentargiftserum kann festgestellt werden, dass in diesem letzten Falle in der Placenta das Glykogen bei weitem stärker abnimmt als in der Leber.

Vergleicht man diese Ergebnisse mit denen der in der 2. Mitteilung der vorliegenden Untersuchung zitierten Autoren bezüglich des Glykogens in der normalen und der eklamptischen Placenta, so stehen die meinen bis in die kleinsten Einzelheiten hinein mit denen jener Autoren im Einklang. Das führt mich zu der Vermutung, dass das eklamptische Placentarglykogen nicht einfach durch Krämpfe usw. verbraucht wird, sondern zwecks Ausübung der Entgiftungswirkung, mit anderen Worten, infolge der spezifischen Wirkung auf die Placenta vermindert wird.

Eine Zusammenfassung der in der-III.-V. Mitteilung vorliegender Untersuchung besprochenen Versuchsergebnisse zeigt, dass auch das Leber- und das Placentarglykogen entgiftend wirken und die eklamptische Placenta eine weit kleinere Menge Glykogen enthält als die normale. Zur Entscheidung der Frage, ob dieser Befund an der Placenta, wie erwartet, der Eklampsie eigentümlich ist oder einfach von eklamptischen Krämpfen herrührt, muss man das Glykogen der Placenta 1) bei von Krämpfen freier Eklampsie und 2) bei spastischeri Wehen messen. Angenommen, Glykogen käme bei jener sehr spärlich vor und bei dieser nicht so wenig, so könnte man den kleinen Glykogengehalt der eklamptischen Placenta nicht einfach als Folge der Krämpfe, sondern der Eklampsie betrachten. Da ich aber solchen Fall nicht hatte, so habe ich einerseits experimentell die Verhältnisse der von Strychninkrämpfen herrührenden Placentarglykogenabnahme, andererseits den Einfluss des Placentargiftserums auf dies untersucht, was ergab (IV. u. V. Mitteilung), dass bei langdauernden und starken Strychninkrämpfen das Placentarglykogen bis auf $0,6-0,85 \%$ vermindert wurde und auch infolge von Placentargiftserum bedeutend abnahm $(0,36-0,68 \mathrm{mg} \%)$. Obwohl diese Strychninkrämpfe bei weitem stärker sind und länger dauern, so kann man doch erkennen, dass die Wirkung des schwächer spasmogenen Placentargiftserums auf beide Placentarglykogenmengen kleiner ist. Auf Grund dieses Versuchsergebnisses vermute ich, dass der Grund für die kleine Menge des eklamptischen Placentarglykogens nicht nur einfach in den Krämpfen, sondern auch darin gesucht werden muss, dass die eine Hälfte des Glykogens zur entgiftenden Wirkung verbraucht wird.

Schliesslich geraten, wenn Hepatotoxin oder Placentargiftserum allein eingespritzt wird, Kaninchen in mehr oder minder krampfähn- 
liche Zustände (Seitenlage, laufähnliche Bewegungen und tetanische Streckungen der Hinterextremitäten), aber besonders stellen sich, wenn 4 Tage nach der Einspritzung von Hepatotoxin auch noch $\mathrm{Ka}$ ninchenplacentargiftserum injiziert wird, heftige Krämpfe und Zukkungen an der Bauchwand ein. Dadurch gelange ich zu der Mutmassung, dass die Symptome nicht nur stark sind, sondern dass auch, da das Placentarglykogen noch ausgesprochener als das Leberglykogen abnimmt das Kaninchenplacentarimmunserum mindestens die Kaninchenplacenta spezifisch beeinflusst und dass bei mehr oder minder starker Störung der Leber dieser schlechte Einfluss noch verstärkt wird. Das erinnert daran, dass die Abnahme des Leber- und Placentarglykogens mit dem Wesen der Eklampsie mehr oder minder zusamrnenhängt.

An Theorien über das Wesen der Eklampsie gibt es sehr viele: die Urämietheorie (Frerichs, ${ }^{28)}$ Spiegelberg ${ }^{227}$ und die Eklampsiebakterientheorie Doléris et Pone $y^{30)}$ und Stroganof $f^{31)}$ ), die Theorie der Vergiftung der Stoffwechselprodukte, die Gefässfunktionsstörungstheorie, die Habitusanomalietheorie oder die Theorie, welche die Funktionsstörung der innersekretorischen Drüsen annimmt Nicholson, ${ }^{32}$ Vassale ${ }^{33)}$ Masa glia ${ }^{8+5}$ Westermark ${ }^{35)}$ u.a.). Die Gründe für diese angeführten Theorien sind ungeheuer mannigfaltig.

Wenn die Eklampsie eine Krankheit ist, deren Ursprung ausschliesslich in der Schwangerschaft liegt und für die das Embryonalleben eine unerlässliche Vorbedingung ist, so kann niemand in Abrede stellen, dass die Eklampsie den Grund zur intrauterinen Neubildung der embryonalen Organe legt. Dass sich bei normaler Schwangerschaft auch ohne Auftreten von Anomalien im ganzen Verlaufe intensive Symptome von Eklampsie einstellen, beruht vermutlich auf embryonalen Einflüssen. Essen ${ }^{36}$ ) behauptet wohl mit Recht, dass die Entstehung der Eklampsie auf das Ei zurückzuführen sein dürfte, also die Erforschung der Placenta notwendig sei. Angenommen, durch vorliegende Untersuchung wären die entgiftende Wirkung des Leber- und Placentarglykogens, der sehr geringe Glykogengehalt des eklamptischen Mutterkuchens und der Umstand, dass diese Abnahme des Glykogens nicht einfach Folge von Krämpfen, sondern der Placentargiftwirkung ist, experimentell erwiesen, so wäre das Wesen der Eklampsie nur auf Grund dieser Versuchsergebnisse nicht noch ohne weiteres klar. Hingegen kann m. E. mit Recht behauptet werden, dass die Abschwächung der entgiftenden Wirkung der Placenta und der Leber an der Eklampsieentstehung teilnimmt, mindestens fördernd darauf wirkt. 


\section{Schluss.}

Hier seien aus den in der 1.-3. Mitteilung erörterten Versuchsergebnissen folgende Schlüsse gezogen:

1. Das Leber- und das Placentarglykogen nehmen, mit der Entgiftung gleichen Schritt haltend, zu und ab.

2. Der Glykogengehalt der eklamptischen Placenta ist bei weitem kleiner als der der normalen.

3. An Tieren, die sich in der zweiten Hälfte der Trächtigkeit befanden, konnten durch Injektion zuerst von Hepatotoxin, dann von Placentargiftserum, wenn auch keine vollkommenen, eklampsieartige krankhafte Veränderung'en hervorgerufen werden.

Am Schluss dieser Arbeit spreche ich meinem hochverehrten Lehrer, Prof. Dr. T. I shika wa, für seine liebenswürdige Leitung bei dieser Arbeit und seine gründliche Verbesserung dieses Manuskripts meinen herzlichsten Dank aus.

\section{Literatur.}

(1) Sakurabayashi, Tohoku Igaku Zasshi, 1926, 9, 1.

(2) Pearce and J a ckson, Journ. of Exp. Med., 1907, 9, 552.

(3) Willi a m, Journ. of Am. Med. Ass., 1921, 76, 1297.

(4) Walthard, Arch. f. Gyn., 1923, 116, 68.

(5) Fetzer, Verhandl. d. deutsch. Gesell. f. Gyn., 1914, 15, T. 2, 137.

(6) Meyers, in Hinselman n, Die Eklampsie, Bonn 1924, S. 111.

(7) Shibaya ma, Nippon Fujinka Gakkai Zasshi, 1927, 22, 575.

(8) A kiy a ma, Nippon Fujinka Gakkai Zasshi, 1927, 22, 1190.

(9) Hellmuth, Arch. f. Gyn., 1923, 118, 18.

(10) Hohlwe g, Med. Kl., 1915, 11, 331.

(11) He gneman n, Zeitsehr. f. Geb. u. Gyn., 1912, 71, 110.

(12) Bunker and M u nde11, Journ. of Am. Med. Ass., 1924, 83, 836.

(13) Stander und R adelet, Bull. of Johns Hopkins Hosp., 1926, 38, 423.

(14) P l as s, Bull. of John Hopkins Hosp., 1924, 35, 345.

(15) Za ngemeister, Beiträge z. Geb. u. Gyn., 1901, 5, 310; Zeitschr. f. Geb. u. Gyn., 1903, 49, 92 ; Zeitschr. f. Geb. u. Gyn., 1903, 50, 385.

(16) Landsberg, Areh.f. Gyn., 1910, 92, 693; Zeitschr. f. Geb.u.Gyn., 1915, 76, 53.

(17) Folin, Journ. of the Am. Med. Ass., 1917, 63, 1209.

(18) Y a mad a, Nippon Fujinka Gakkai Zasshi, 1924, 19, 412.

(19) Deneck, in Hinselmann Die Eklmpsie, Bonn 1924, S. 293.

(20) Stander und Harris on, Am. Journ. of Obst. a. Gyn., 1929, 18, 17.

(21) Benthin, Monatschr. f. Geb. u. Gyn., 1913, 37, 305.

(22) Ryser, Deutsch. Arch. f. kl. Med., 1916, 118, 408.

(23) Widé n, Monatsschr. f. Geb. u. Gyn., 1915, 41, 113.

(24) Titus, D od ds und Willetts, Am. Journ. of Obst, a. Gyn., 1927, 14, 89.

(25) Titus und Lightb ody, Am. Journ. of Obst. a. Gyn., 1929, 18, 208.

(26). Berg s ma, Zeitschr. f. Geb. u. Gyn., 1912, 72, 105.

(27) O bata und Hay as i, Nippon Fujinka Gakkai Zasshi, 1922, 17, 222. 
(28) Frerichs, Die Brightsche Nierenkrankheit, Brannschweig 1851.

(29) Spiegelberg, Arch. f. Gyn., 1878, 1, 383.

(30) Doléris und Poney, Soc. Biol. Paris, 1885, 489.

(31) Strogan off, Berl, kl. Wochenschr, 1902, 39, 154.

(32) Nichols o n, Lancet, $1901,1831$.

(33) Vassale, zit. nach Halban-Seitz, Biologie u. Pathologie des Weibes, Berlin u. Wien, 1927 Bd. 7, T. 1. 944

(34) Massaglia, Endocrinology, 1921, 5, 309.

(35) Westermark, Arch. f. Gyn., 1919, 110, 517.

(36) Essen, zit. nach $\mathrm{H}$ a lban-Seitz, Biolologie n. Pathologie des Weibes, BerIin u. Wien Bd, 7, T. 1. S. 907, 1927.

(37) Farr and Williams, Jour. of Amer. Med. Assoc., 1921, 76. 